\title{
International Journal of Engineering
}

\author{
Journa l H o m e pag e: w w w. i je.i r
}

\section{Modeling and Optimization of Charge Materials Ranges in Converter Furnace with Enhanced Passivation Time in Copper Electrorefining Process: A Mixture Design Approach}

\author{
M. H. Khazaei Feizabad*a, G. R. Khayatia, R. Kafi Hernashkic, S. M. J. Khorasanid \\ a Department of materials science and Engineering, Shahid Bahonar University of Kerman, Kerman, Iran \\ ${ }^{b}$ Research and development center, shahrebabak copper complex, national Iranian copper Industries company, Kerman, Iran \\ ${ }^{c}$ Research \& Development Center, Shahrebabak Copper Complex, National Iranian Copper Industries Company, Kerman, Iran \\ d Senior metallurgical engineer, Process control unit, Khatoonabad copper refinery, Shahrebabak copper complex, National Iranian copper \\ industries company, Kerman, Iran
}

\section{$P A P E R \quad I N F O$}

\section{Paper history:}

Received 21 September 2020

Received in revised form 26 January 2021

Accepted 13 February 2021

\section{Keywords:}

Copper Electrorefining

Passivation Time

Casting Anode

Design of Experiment

\author{
$A B S T R A C T$
}

In this study, the design of experiments is used to study and model the time of passivation in copper electrorefining as a function of the charge of melting furnace through the preparation of copper casting anodes. As a result of optimization for the proposed optimized anodes, the charge percent values of concentrate (Co), refinery scrap (RS), and non-refinery scrap (NRS) were proposed equals to 69.1, 0.574 and 30.32 (wt.\%), respectively. Experimental data confirmed the enhanced passivation time of the proposed anode was $6520 \mathrm{~s}$. Also, it was observed that the molar ratio of $\mathrm{As} /(\mathrm{Bi}+\mathrm{Sb})$ and $\mathrm{Ag} /(\mathrm{Se}+\mathrm{Te})$ are the key factors in passivation time. Finally, the relation of passivation time (seconds) with the charge of melting furnace is proposed as $: \mathrm{t}(\mathrm{s})=-3728.98 \times \mathrm{Co}+4640.00 \times \mathrm{RS}+3141.00 \times \mathrm{NRS}+17763.27$ $\times \mathrm{Co} \times \mathrm{RS}+25547.65 \times \mathrm{Co} \times \mathrm{NRS}-1758.00 \times \mathrm{RS} \times \mathrm{NRS}$. Moreover, adding of As ingot in casting anodes as a dose dependent of non-refinery scrap portion in the input charge of the melting unit can effectively prolong the time of passivation.

doi: $10.5829 /$ ije.2021.34.04a.23

\section{INTRODUCTION}

Almost all produced copper by different methods including hydrometallurgy or pyrometallurgy, experience an electrolytic step. The former uses the electrolytic step through the production of pure copper from the impure casting anode by the electrorefining process. While the later uses the electrolytic step through the electrowinning process [1-3].

The electrorefining process involves two general steps. The first step is the anodic electrochemical dissolution of impure copper in an electrolyte containing $\mathrm{H}_{2} \mathrm{SO}_{4}$ and $\mathrm{CuSO}_{4}$ and the second step is the deposition of pure copper on the cathode. In this process, pure copper is produced and also, valuable impurities are removed from the impure copper as anodic slime [1, 2, 4]. Copper anodes with a purity of 98.5 to $99.5 \%$ is used to produce a copper cathode with a purity of more than $99.997 \%$ in the electrorefining process [1].

Passivation is one of the most important problems in the industrial electrorefining plant. It refers to a sudden increase in the applied cell voltage. This problem may be due to the formation and accumulation of various nonconductive corrosion products at the anode surface. This passive layer acts as diffusion barriers and prevents the diffusion of copper ions from the anode to the cathode. In this condition, the production capacity reduces and increases energy consumption. It also increases the amount of slime in the electrolyte, which can reduce the quality of the produced cathode. The anode dissolution stops or becomes very slow during the passivation while the electrorefining process is not yet completed. These results cause a lot of energy and work

*Corresponding Author Institutional Email: m.h.khazaei@eng.uk.ac.ir (M. H. Khazaei Feizabad) 
loss because the anode has to be removed and melted again [5-13].

In industrial conditions, pure copper anodes cannot be passivated, so anode impurities are the main reason for industrial passivation. These impurities originated from the charges of the melting furnace. When dissolving the anode, some of these impurities appear as slime and the rest dissolve in the electrolyte. Such impurities increases in the electrolyte over time and real-time purification of electrolyte is necessary [1, 5-7].

Due to the electrochemical nature of the electrorefining process, different electrochemical methods are used to study the passivation behavior of the casting anode. Cyclic voltammetry (CV), linear potential sweep (LPS), and galvanostatic or chronopotentiometry (CP) measurement are the most important of these methods. Since the most important cause of passivation is the presence of impurities, the method that is more sensitive to impurities is more suitable for studying of passivation $[9,14]$. It is shown that the $\mathrm{CP}$ is the most sensitive method and provides the best quantitative data for anode passivation [14]. Also, this technique determines the "passivation time" in an experimental condition that can be used as a criterion for comparison of the anode passivation at the industrial condition.

There are various techniques for optimizing the experimental processes. All of them provide the conditions with the minimum number of tests without a significant impact on the accuracy of the measurement. Also, these techniques provide the possibility of determination of optimum condition. Response surface methodology was proposed employed to design the experiments through the collecting data [15]. It is one of the most promising approaches in the case that the operational factors consider as ingredients of the mixture and the response is a dependent proportions function [1620]. Low operating costs due to the reduction in the number of required tests and provide the possibility of the simultaneous changes in variables are the main advantages of this approach [21, 22]. To the best of our knowledge, despite extensive studies on the anode passivation, it is suffered from the systematic investigation about the optimization of proposed compounds .

The charge of copper anode casting furnace in the Khatoonabad copper refinery of Iran is supplied from three sources including concentrate $(\mathrm{Co})$, refinery scrap (RS), and non-refinery scrap (NRS), which can be charged in a different ratio. In this study, the effect of each charging source is estimated on the occurrence of passivation using the mixture method as one of the most promising approaches in the design of experiments. Then, the passivation of the casting anode is exanimated by $\mathrm{CP}$.

\section{MATERIALS AND METHODS}

According to the literatures [6-12], the most important factor affecting the passivation of industrial anodes is their chemical composition. The chemical composition of the anodes is determined at the casting machine, so the input materials of the melting furnace must be studied to evaluate the effect of the chemical composition. In the Khatoonabad copper complex of Iran, the entrance of the smelting furnace includes Co, RS, and NRS. In this case, to change the chemical composition, the input component of the furnace charge must be changed. Therefore, to study the effect of input and determine the appropriate composition to increase the onset time of passivation, the experimental design method can be used.

Since in this study, the total input of the furnace is fixed and only the fraction of each input change, the mixture experiment design method should be used as a powerful method in examining and optimizing the inputs of the smelting unit. This method can be used to determine the optimal charge ratio in the melting furnace to increase the passivation time. According to the limit announced by Khatoonabad copper complex for each of the inputs of the smelting furnace, the limits of the inputs of the furnace are considered according to Table 1 .

According to the proposed model by mixed design, the relationship between the passivation time and melting furnace charge can be presented as a polynomial model. It should be noted that the total amount of furnace charge components must be equal to 100 . Due to these limitations, the polynomial model can be presented in a standard form. Equation (1) presents the standard model:

$$
\begin{aligned}
& \mathrm{Y}^{*}=\mathrm{b} 1 \mathrm{X} 1+\mathrm{b} 2 \mathrm{X} 2+\mathrm{b} 3 \mathrm{X} 3+\mathrm{b} 12 \mathrm{X} 1 \mathrm{X} 2+\mathrm{b} 13 \mathrm{X} 1 \mathrm{X} 3 \\
& +\mathrm{b} 23 \mathrm{X} 2 \mathrm{X} 3+\mathrm{b} 123 \mathrm{X} 1 \mathrm{X} 2 \mathrm{X} 3
\end{aligned}
$$

where $\mathrm{Y}=\mathrm{Y} *+\mathrm{e}$ and $\mathrm{X} 1, \mathrm{X} 2$, and $\mathrm{X} 3$ are the selected parameters through modelin.

Design-Expert software is used to design the experiments through the data collection. Table 2 shows 7 experiments that proposed by Design-Expert Software. For each of the experiments, the passivation time of the samples is measured, separately by chronopotentiometry analysis. To estimate the error of analysis, one of the experiments is repeated, randomly (in this study A7).

All samples polish completely to remove the effect of the sample morphology. According to the discussions,

TABLE 1. Range of furnace charge component (Concentrate: Co, Refinery scrap: RS, Non-refinery scrap: NRS)

\begin{tabular}{lcc}
\hline Charge of furnace & Lower limit & Upper limit \\
\hline Co & 50 & 85 \\
RS & 0 & 50 \\
NRS & 0 & 50 \\
\hline
\end{tabular}


TABLE 2. Experimental design performed in the current study

\begin{tabular}{lccc}
\hline Run & Co & RS & NRS \\
\hline A1 & 50 & 25 & 25 \\
A2 & 50 & 0 & 50 \\
A3 & 85 & 15 & 0 \\
A4 & 50 & 50 & 0 \\
A5 & 85 & 0 & 15 \\
A6 & 67.5 & 32.5 & 0 \\
A7 & 85 & 0 & 15 \\
\hline
\end{tabular}

the chemical composition is the most effective factor in the passivation process, so to determine the exact chemical composition of the prepared samples in the previous step, the quantometer analysis is used .

The galvanostatic test uses to investigate the electrochemical behavior of prepared samples. In this technique, the potential fluctuations of the sample at constant current density are measured. A platinum electrode is used as a cathode to reduce the cathode effect through the process. Due to its high resistance to the chemical reactions, platinum does not affect the process and uses only as a current transfer in the electrochemical circuit. All prepared samples in the previous steps are used as anodes. The anode surface in contact with the electrolyte solution is $1 \mathrm{~cm}^{2}$. Other surfaces of all samples are coated to ensure that other surfaces of the sample are not affected by the test.

The electrolyte uses in this research is the industrial electrolyte of the Khatoonabad copper complex, which has a combination of $180 \mathrm{~g} / \mathrm{l}$ sulfuric acid and $45 \mathrm{~g} / \mathrm{l}$ copper. Additives of the electrolyte are glue, thiourea, and chloride ions. The amounts of glue and thiourea are $95 \mathrm{~g} / \mathrm{ton}$ and $110 \mathrm{~g} / \mathrm{ton}$ of cathodic copper, respectively. Also, the amount of chloride ion is kept constant to be about $40 \mathrm{ppm}$ in the electrolyte. To simulate the electrolyte motion at the industrial electrorefining cell, a magnetic stirrer device is used at the speed of $100 \mathrm{rpm}$. Also, similar to the industrial conditions, the electrolyte temperature is kept constant at $62{ }^{\circ} \mathrm{C}$ during the process. Moreover, the samples are tested for $7200 \mathrm{~s}$ at a current density of $220 \mathrm{~mA} / \mathrm{cm}^{2}$. In this research, an EG \& G 263A potentiostat/galvanostat device is used. To accurately investigate the potential fluctuations, a ternary arrangement of electrodes has been used. This arrangement consists of three electrodes. The auxiliary electrode is the platinum cathode, the working electrode is the copper sample prepared as the anode, and the third electrode is the reference electrode. To increase the accuracy of potential measurement, the sample potential should be measured relative to a reference electrode with a constant potential i.e., a $\mathrm{Hg} / \mathrm{Hg}_{2} \mathrm{Cl}_{2}$ calomel in this study .
Given the engineering knowledge and experience, the Khatoonabad copper refinery uses a mental model based on the operator's skills to add the As ingot through the melting and preparation of casting anodes. In this pattern, arsenic added proportional to the portion of NRS in the charge of melting furnace, this mental pattern significantly affects the processing efficiency and is dependent variables. Accordingly, it is not considered as independent parameters.

\section{RESULTS AND DISCUSSION}

3. 1. Galvanostatic Study The prepared samples, which have an industrial composition, are subjected to a current density of $220 \mathrm{~mA} / \mathrm{cm}^{2}$. The reason for the use of such a high density that accelerates the dissolution rate is the limitations of operating time through the electrochemical tests. Figure 1 shows the chronopotentiometry diagrams of casted anodes samples. All diagrams have three distinct regions including the active zone, the pre-passive zone, and the passive zone.

The passive mechanism can be summarized as that when the casting anode is dissolved, the anode slime begins to release at the anode surface, the active regions decrease, and the current density increases. Also, the concentration of copper at the anode surface increases. When the concentration of copper exceeds the saturation at the electrode surface, it begins to precipitate on the surface of the anode and inside the slime. As a result, slime and copper sulfate cover the surface of the anode. The formation of a sulfate layer on the surface of the electrode allows the oxide layer, which is only stable under certain conditions, to form below the surface of the sulfate layer. But with the formation of the sulfate layer, the copper concentration of the anode surface decreases, which can lead to the re-dissolution of the sulfate layer. If there are no suitable conditions for the stability of the oxide layer when the sulfate layer is dissolved, this layer will also dissolve in the electrolyte. However, if the potential of the oxide layer is sufficiently increased after the sulfate layer is dissolved, the oxide layer does not dissolve and the sample becomes passive. Due to this passive mechanism, any factor that disrupts these phenomena increases the passivation time. In some of the samples, the active dissolution and passivation process repeated several times that is the result of the separation of the anode slime.

In the active region, the dissolution of the metal anode occurs at the high current densities. Copper dissolution with the following reaction can create a passive stable layer of $\mathrm{Cu}_{2} \mathrm{O}$ due to the low potential of reaction (2):

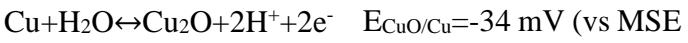

Although there is no change in the appearance of potential in the active region and it is constant, in this 

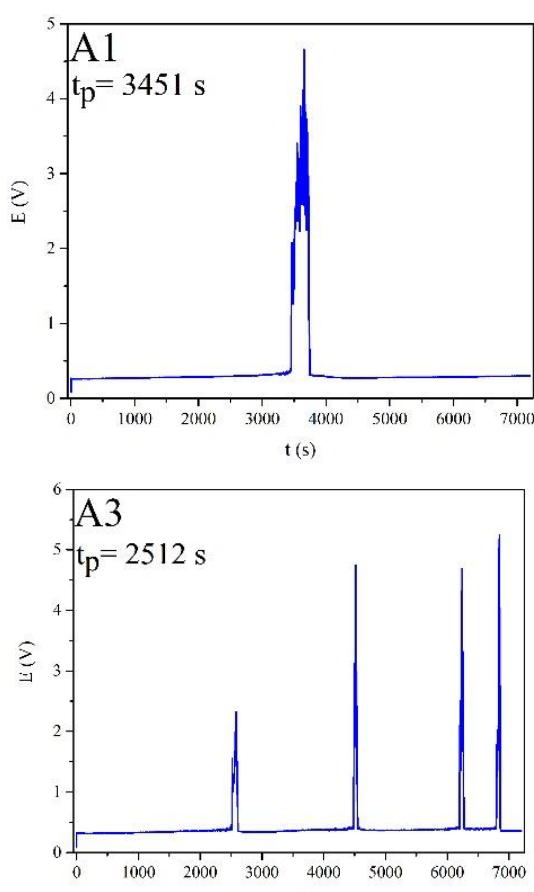

$1(\mathrm{~s})$

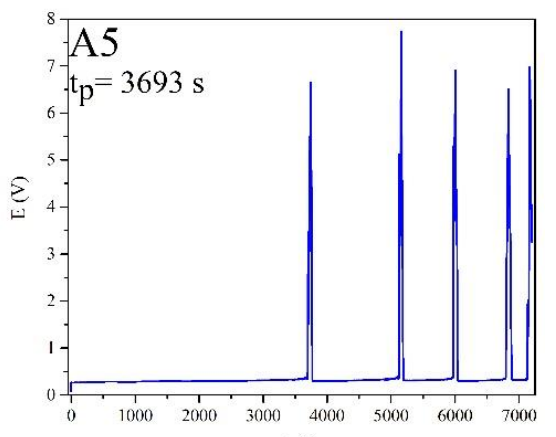

t(s)
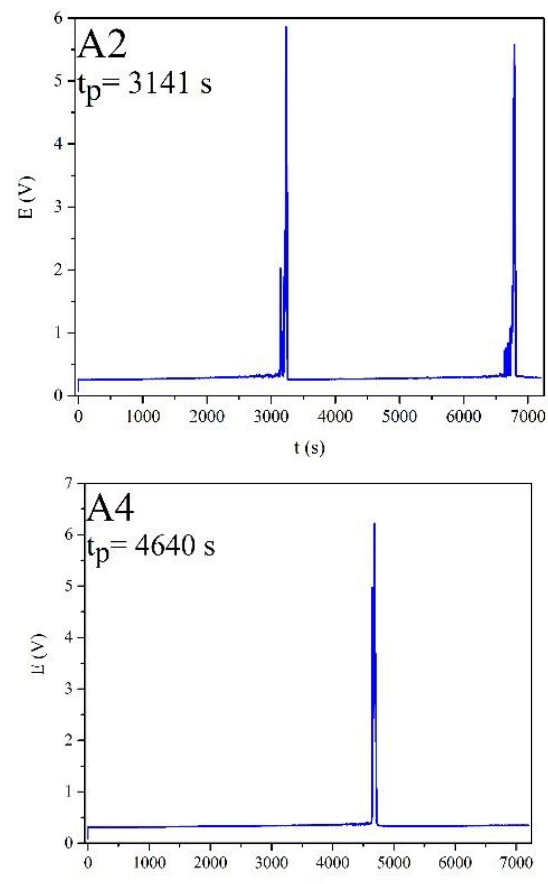

t(s)

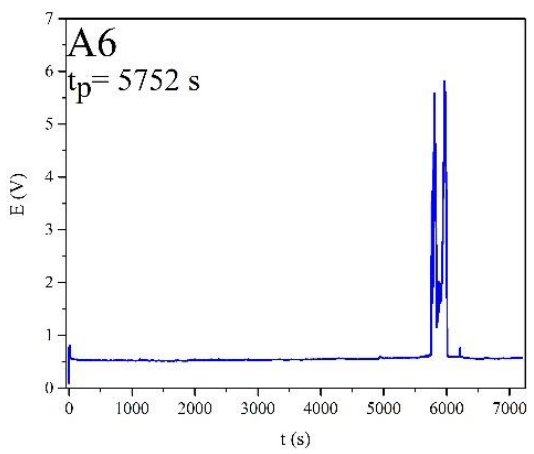

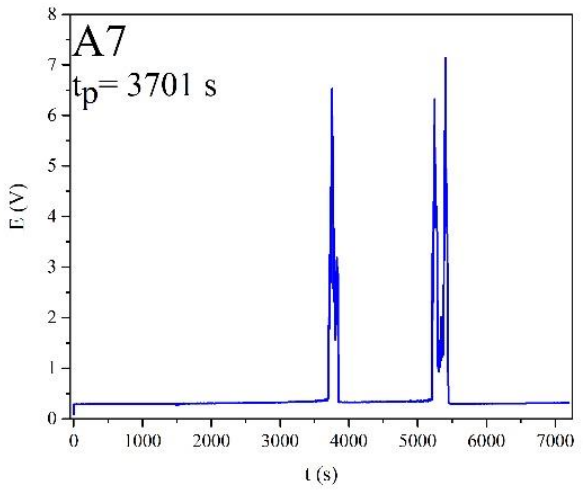

Figure 1. The chronopotentiometry analysis of prepared samples

region the potential increases with a small slope relative to the time. It should be noted that applying a constant current density to dissolve copper does not mean a fixed corrosion rate during the test. Corrosion rates can change during the following condition [6]:
1. The presence of different reactions that consume the currents:

$$
\begin{aligned}
& \mathrm{Cu} \rightarrow \mathrm{Cu}^{2+}+2 \mathrm{e}^{-} \\
& \mathrm{Cu} \rightarrow \mathrm{Cu}^{+}+\mathrm{e}^{-}
\end{aligned}
$$


The formation of $\mathrm{Cu}^{+}$ions dissolves twice the amount of copper relative to $\mathrm{Cu}^{2+}$ at a constant current. The equilibrium between the concentrations of these two copper ions in the solution is expected to be stable at $25^{\circ} \mathrm{C}$ based on the following relationship (Equation (5)):

$$
\frac{\left[\mathrm{Cu}^{2+}\right]}{\left[\mathrm{Cu}^{+}\right]^{2}}=10^{6.9}
$$

$\mathrm{Cu}^{+}$consumption increases with $\mathrm{Cl}^{-}$or anode impurities such as $\mathrm{Se}$, and increases the rate of $\mathrm{Cu}^{+}$formation, which can accelerate the copper dissolution;

2 . The surface of the anode is covered with various corrosion products, which reduces the active level of the anode and leads to an increase in the current density at the active levels;

3. The presence of different phases in the anode microstructure, which is quite conceivable due to the different chemical composition of the industrial anodes, can lead to a different corrosion rate in the samples. The presence of impurities causes more current consumption;

4. Increasing the surface roughness of the anode can lead to an increase in the anode surface during the corrosion, thus reducing the density of the applied current. However, in this study, an attempt has been made to reduce the effect of this factor as much as possible by polishing the surface of the samples.

In the pre-passive zone, anode dissolution and deposition of corrosion products occur sequentially, resulting in the formation of a passive layer with temporary stability on the anode surface. Given the gradual increase in potential, it is expected that the dominant response at this stage will be the formation of $\mathrm{CuO}$ as a product with less stability and greater dissolution. The reaction is as follows (Equation (6)):

$\mathrm{Cu}+\mathrm{H}_{2} \mathrm{O} \leftrightarrow \mathrm{CuO}+2 \mathrm{H}^{+}+2 \mathrm{e}^{-} \quad \mathrm{E} \mathrm{CuO} / \mathrm{Cu}=-34 \mathrm{mV}$ (vs MSE)

This oxide is gradually formed in the cavities of the passive layer $\mathrm{Cu}_{2} \mathrm{O} . \mathrm{Cu}^{2+}$ saturation at the surface of the passive metal causes the formation of $\mathrm{CuSO}_{4}$. Increasing the level of $\mathrm{Cu}^{+}$ions in the surface causes the following reaction (Equation (7)) and the formation of copper powder.

$$
2 \mathrm{Cu}^{+} \leftrightarrow \mathrm{Cu}^{2+}+\mathrm{Cu}
$$

At this condition, copper sulfate and copper powder cover the surface of the copper oxide layer. Thus, anodelevel products generally include copper powder, copper sulfate, and copper oxide $\left(\mathrm{CuO}\right.$ and $\left.\mathrm{Cu}_{2} \mathrm{O}\right)$, as well as the other additional components due to the impurities of the anode compound.

Figure 2 shows a free corrosion diagram of a copperwater system at $25^{\circ} \mathrm{C}$. Various parameters such as temperature, corrosion formation on the surface and their accumulation near the surface, lack of penetration due to low excitation, and the effect of additives on the surface can change the $\mathrm{pH}$ of the reaction near the surface. In

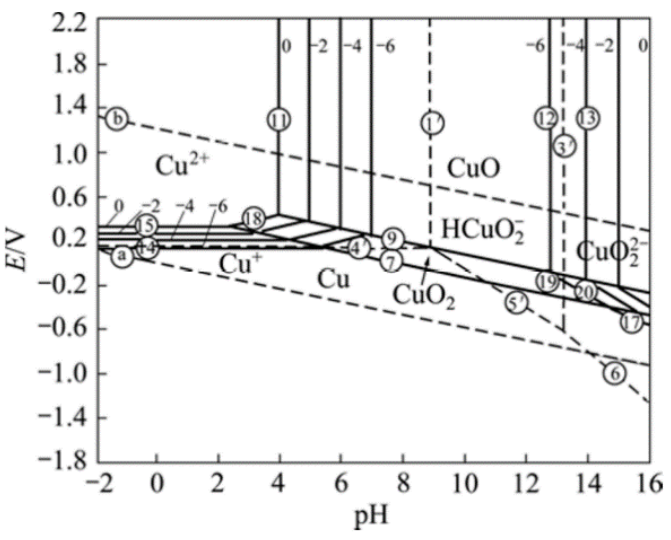

Figure 2. Purbe's diagram of $\mathrm{Cu}-\mathrm{H}_{2} \mathrm{O}$ system at $25^{\circ} \mathrm{C}[6]$

addition, the high current density of $220 \mathrm{mV} / \mathrm{cm}^{2}$ determines the dominant reaction of the trans-passive region of the Purbe diagram, while this graph generally explains the active-passive region. All of these parameters cause a sudden change in $\mathrm{pH}$ near the surface where different reactants such as $\mathrm{Cu}_{2} \mathrm{O}, \mathrm{Cu}^{+}$, and impurities such as $\mathrm{Sb}_{2} \mathrm{O}_{3}$ and $\mathrm{Bi}_{2} \mathrm{O}_{3}$ consume the acid at the joint level of the metal with the solution. Finally, according to Purbe's diagram (Figure 2), increasing the $\mathrm{pH}$ leads to the stability of $\mathrm{Cu}_{2} \mathrm{O}$. In the passive region, the formation of a stable $\mathrm{Cu}_{2} \mathrm{O}$ layer is the predominant reaction. It should be noted that in this area, the reaction is accelerated (Equation (8)) in the presence of oxygen.

$$
1 / 2 \mathrm{O}_{2}+\mathrm{Cu}_{2} \mathrm{O} \rightarrow 2 \mathrm{CuO}
$$

After the passive region, several active-passive unstable steps are observed again. This can be due to the inadequacy of passive products on the common metalsoluble surface. Also, the lack of sufficient adhesion of the products can lead to the separation of the passive layer and the creation of the next active-passive steps.

Figure 3 shows the first and second regions of the chronopotentiometry diagram, the active and pre-passive regions of the tested samples. Although the potential changes in the chronopotentiometry chart appear to be constant in the first and second regions, in fact, the potential in these areas is increasing with a slight slope. This increase in potential could be due to the formation of corrosion products and the release of sludge at the anode level, which leads to an increase in potential. Observations show that increasing the slope of the first zone eventually leads to accelerated passivation. Sample 6 has the least slope changes between the samples and the longest passivation time. The reason for this can be stated in the arsenic value of this sample. Increasing arsenic reduces the adhesion of corrosion products and separates them from the surface, which can reduce the slope of the potential increase and increase the passivation time. 
3. 2. Modeling of Passivation Time The time of passivation, i.e., the experiment design response, were added to Figure 2. Equation (9) indicates the proposed model for determining the time of passivation in terms of melting load furnace.

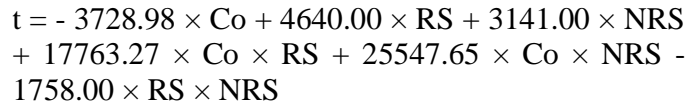

ANOVA analysis is one of the most widely used methods of analysis in statistical studies. This analysis is a powerful tool for estimating the statistical models due to the distribution of experimental data obtained in this method. In this study, the model provided for passivation time has a $\mathrm{P}$-value equal to 0.0037 , which indicates that the model is acceptable. Table 3 shows ANOVA analysis for the passivation time of prepared samples.

According to the proposed software model, the predicted values of the passivation time of samples with different furnace load combinations are shown in Figure 4.

The chemical compositions of prepared samples are abbreviated in Table 4. As it turns out, the chemical composition of the samples is very wide, and it is clear that it has a complex relationship with the furnace loads. Because of the complexity of the relationship between furnace input and anode chemical composition, the experimental design method can be a good way to examine and process the data.

TABLE 3. the ANOVA analysis for passivation time of prepared samples

\begin{tabular}{|c|c|c|c|c|c|c|}
\hline $\begin{array}{l}\text { Source of } \\
\text { variation }\end{array}$ & Sum of Squares & Df & Mean Square & F-Value & P-Value & Significant \\
\hline \multicolumn{7}{|c|}{ Response $\mathrm{Y}_{1}$} \\
\hline Model & $6.740 \mathrm{E}+006$ & 5 & $1.348 \mathrm{E}+006$ & 42125.84 & 0.0037 & Significant \\
\hline Linear Mixture & $2.391 \mathrm{E}+006$ & 2 & $1.196 \mathrm{E}+006$ & 37361.58 & 0.0037 & \\
\hline $\mathrm{AB}$ & $3.157 \mathrm{E}+006$ & 1 & $3.157 \mathrm{E}+006$ & 98645.33 & 0.0020 & \\
\hline $\mathrm{AC}$ & $3.949 \mathrm{E}+006$ & 1 & $3.949 \mathrm{E}+006$ & $1.234 \mathrm{E}+005$ & 0.0018 & \\
\hline $\mathrm{BC}$ & $1.288 \mathrm{E}+005$ & 1 & $1.288 \mathrm{E}+005$ & 4024.17 & 0.0100 & \\
\hline Pure Error & 32.00 & 1 & 32.00 & 12.06 & 0.1785 & \\
\hline Cor Total & $6.740 \mathrm{E}+006$ & 6 & & & & \\
\hline
\end{tabular}

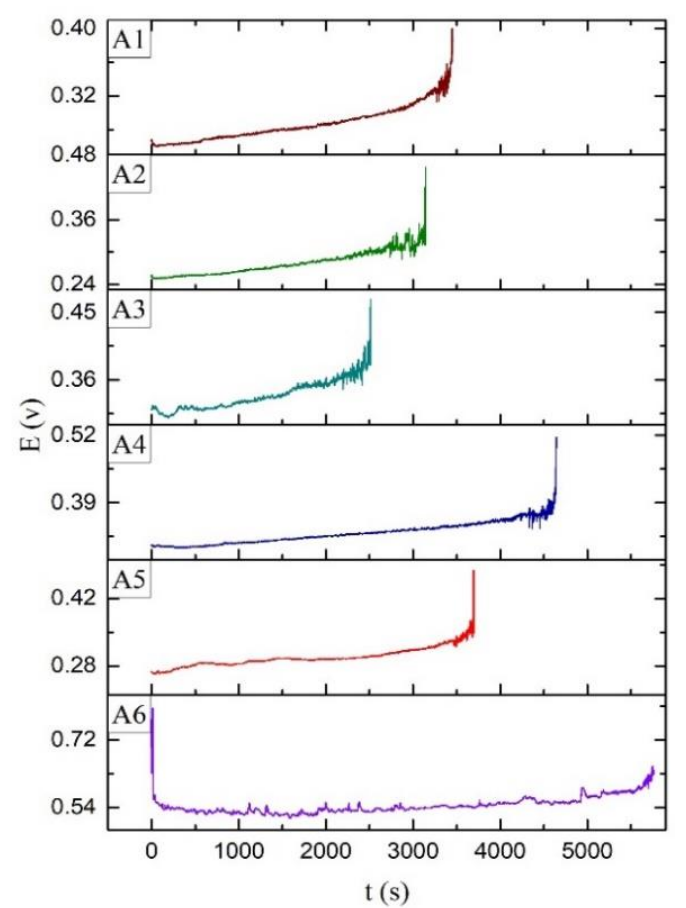

Figure 3. Illustration of the active and pre-passive region in various samples

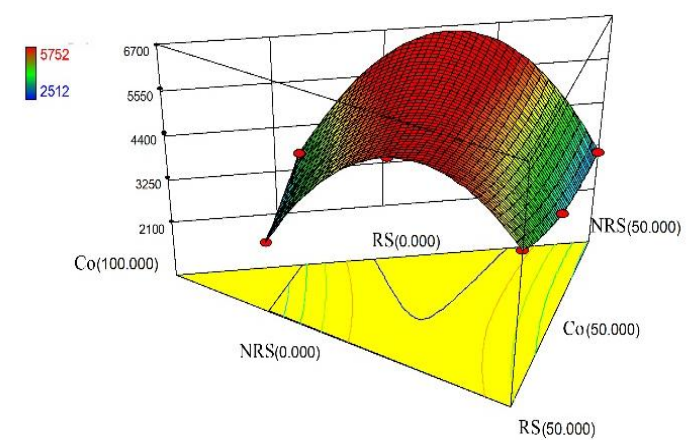

Figure 4. 3D profile of passivation time versus the load charge of melting furnace

The highest passivation time in the experiments performed according to Figure 3 is related to the A6 sample. As shown in Table 4, this sample has the highest amount of As. Research has shown that the presence of As in the compound can reduce the adhesion of the slime layer and cause the layer to separate from the anode surface [11]. Also, As is an acid-forming element based (Equation (10)). Decreasing the $\mathrm{pH}$ of the electrolyte leads to the instability of the copper oxide and its 
TABLE 4. Chemical combination of prepared samples

\begin{tabular}{cccccccccccccccccccccccccccccccc}
\hline & $\% \mathbf{C u}$ & $\mathbf{P}$ & $\mathbf{S}$ & $\mathbf{T e}$ & $\mathbf{A s}$ & $\mathbf{S e}$ & $\mathbf{S b}$ & $\mathbf{C d}$ & $\mathbf{C r}$ & $\mathbf{P b}$ & $\mathbf{S i}$ & $\mathbf{B i}$ & $\mathbf{A g}$ & $\mathbf{Z n}$ & $\mathbf{N i}$ & $\mathbf{C o}$ & $\mathbf{F e}$ & $\% \mathbf{O}$ & $\mathbf{A u}$ & $\mathbf{S n}$ & $\mathbf{M n}$ \\
\hline A1 & 99.64 & $0.5>$ & 12.53 & 50.0 & 436 & 124 & 211 & $0.5>$ & $0.5>$ & 202 & 7.69 & 8.0 & 239 & 36.77 & 260.5 & 2.43 & 83.86 & 0.1 & 7.44 & 1.43 & 1.23 \\
A2 & 99.55 & $<0.5$ & 8 & 44 & 464 & 119 & 184 & $<0.5$ & $<0.5$ & 200 & $<0.5$ & 8.98 & 244 & 37 & 278 & 1.57 & 69 & 0.19 & 7.94 & $<0.5$ & $<0.5$ \\
A3 & 99.63 & $<0.5$ & 7.39 & 39 & 451 & 122 & 312 & $<0.5$ & $<0.5$ & 165 & $<0.5$ & 11 & 209 & 23 & 263 & 0.5 & 49 & 0.18 & 7.10 & 3.77 & $<0.5$ \\
A4 & 99.66 & $<0.5$ & 19.5 & 48.4 & 451 & 121 & 179 & $<0.5$ & $<0.5$ & 209 & $<0.5$ & 7.22 & 230.7 & 47.5 & 269 & 2.87 & 35.01 & 0.17 & 7.31 & 0.87 & $<0.5$ \\
A5 & 99.66 & $0.5>$ & 3.95 & 32.0 & 419 & 98 & 190 & $0.5>$ & $0.5>$ & 136 & $0.5>$ & 7.36 & 226.3 & 23.47 & 223.9 & $0.5>$ & 62.09 & 0.12 & 7.60 & 8.33 & $0.5>$ \\
A6 & 99.66 & $<0.5$ & 2.76 & 24 & 497 & 68.1 & 336 & $<0.5$ & $<0.5$ & 314 & $<0.5$ & 11.3 & 197.4 & 20.90 & 458.6 & $<0.5$ & 23.3 & 0.13 & 6.50 & 43.16 & $<0.5$ \\
\hline
\end{tabular}

dissolution in the electrolyte, which increases the passivation time.

$$
\mathrm{As}_{2} \mathrm{O}_{3}+3 \mathrm{H}_{2} \mathrm{O} \rightarrow \mathrm{H}_{2} \mathrm{AsO}_{4}+2 \mathrm{H}^{+}+2 e
$$

But as the results of this study showed, As is not the only determining factor in passivation. For example, two samples, A3 and A4, have the same As value with a large difference in passivation time. In other words, the shortest and longest passivation times were respectively belonged to A3 and A4 samples. These two samples even have almost the same amount of $\mathrm{Ni}$, but the important difference between these two samples is the amount of $\mathrm{Sb}$ and $\mathrm{Fe}$ that higher in A3. Sample A3, after the A6 sample with the highest value of As, has the highest $\mathrm{Sb}$ content. $\mathrm{Sb}$ and $\mathrm{Bi}$ are the elements that can be present in the electrolyte in the form of suspended slime. Also, these elements are (Equations (11) and (12)) the acidconsuming elements that can ultimately lead to the stability of the copper oxide layer and reduce the passivation time [23].

$$
\begin{aligned}
& \mathrm{Bi}_{2} \mathrm{O}_{3}+6 \mathrm{H}^{+} \rightarrow 2 \mathrm{Bi}^{3+}+3 \mathrm{H}_{2} \mathrm{O} \\
& 2 \mathrm{Sb}^{3+}+\mathrm{O}_{2}+4 \mathrm{H}^{+}=2 \mathrm{Sb}^{5+}+2 \mathrm{H}_{2} \mathrm{O}
\end{aligned}
$$

Based on the results of this research, it is possible to find a suitable relationship between the process of passivation and certain ratios of alloying elements. The most important ratio of impurities that can affect passivation is the molar arsenic ratio to the sum of $\mathrm{Bi}$ and $\mathrm{Sb}$. This ratio can be used to compare the samples to each other. The lower passivation tendency is observed in anods with the higher values of this molar ratio.

Table 5 shows the calculated ratios of the tested samples. The highest molecular ratio of $\mathrm{As} /(\mathrm{Bi}+\mathrm{Sb})$ belongs to the A4 sample, which has a relatively long passivation time of $4640 \mathrm{~s}$. A2, A5, and A3 have the following values of this ratio, the values of which are also close to each other. Also, A3, in which the value of the ratio is 2.3 , has the shortest passivation time. It is observed that, except for A6, the passive time is strongly dependent on this ratio. A6 has the lowest value of this ratio however shows the longest passivation time. The reason for this could be related to the $\mathrm{Ag} /(\mathrm{Te}+\mathrm{Se})$ ratio in
TABLE 5. The molar ratio of $\mathrm{Ag} /(\mathrm{Se}+\mathrm{Sb})$ and $\mathrm{As} /(\mathrm{Bi}+\mathrm{Te})$ of prepared samples

\begin{tabular}{lcc} 
Sample & $\mathbf{A s} /(\mathbf{B i}+\mathbf{S b})$ & $\mathbf{A g} /(\mathbf{S e}+\mathbf{T e})$ \\
\hline 1 & 3.285 & 1.129 \\
2 & 3.984 & 1.221 \\
3 & 2.301 & 1.046 \\
4 & 4.000 & 1.118 \\
5 & 3.504 & 1.406 \\
6 & 1.741 & 2.357 \\
\hline
\end{tabular}

addition to the effect of As on the separation of the product layer from the anode level. As shown in Table 5, the value of this ratio in A6 is much higher than the others.

It is worth noting that silver is an effective factor for the rapid removal of $\mathrm{Se}$ and $\mathrm{Te}$, which, by forming $\mathrm{Ag}_{2}(\mathrm{Se}+\mathrm{Te})$, transfers these elements to the anodic slimes and prevents them from increasing their contents in the electrolyte. Decreasing this ratio, in the case of reducing the silver content in the input, activates the secondary reaction of removing $\mathrm{Se}$ and Te with significantly slower kinetics in which copper is replaced by silver, and produces $\mathrm{Cu}_{2}(\mathrm{Se}+\mathrm{Te})$. In this condition, due to the slower kinetics than the previous reaction, causes an increase in Se content in the electrolyte. Consequently, the molar ratio of $\mathrm{Ag} /(\mathrm{Te}+\mathrm{Se})$ is an effective factor for passivation. However, it should be noted that the role of $\mathrm{Ag} /(\mathrm{Se}+\mathrm{Te})$ molar ratio on passivation is far less than $\mathrm{As} /(\mathrm{Bi}+\mathrm{Sb})$.

Oxygen content is the next effective factor in the passivation of the anode. Since all samples have the same oxygen content, it is incorrect to address this factor separately. Lead and nickel are the two factors that contribute to the intensification of passivity. Both of them are activated in the presence of oxygen, and their content in A6 is significantly higher than the others. However, the longer the passive time of this sample indicates the greater the effect of the arsenic element, which is higher than in others. Iron is the next element influencing passivation behavior. Since A1 with the highest iron content experienced a relatively long period 
of passivation, this impurity appears to have had little effect in the study area. This indicates that in addition to the high arsenic value of $\mathrm{A} 6$, the higher $\mathrm{Ag} /(\mathrm{Se}+\mathrm{Te})$ ratio along with the lower iron content, could be one of the reasons for a long time of passivation. Because A6 had far less iron content than A1 with the least time spent.

Overall, the results of this study have shown that in industrial anodes, due to the simultaneous presence of high impurities and the interaction of these elements, the results of the times of passivation have a complex relationship with the chemical composition and cannot be easily relied on. The element established a relationship with the time of passivation. This shows the importance of using the design of the experiment in this research.

\section{3. Validation of Proposed Optimum Condition} Since the passivation time in copper anodes must be increased to increase the efficiency of the electrorefining

TABLE 6. Various combination of charge load in the melting unit by as maximum as possible time of passivation

\begin{tabular}{|c|c|c|c|c|c|c|}
\hline Number & Co & RS & NRS & $\mathrm{t}(\mathrm{sec})$ & Desirability & \\
\hline 1 & 63.125 & 0.000 & 36.875 & 6283.48 & 1.000 & \\
\hline 2 & 74.500 & 0.000 & 25.500 & 6159.04 & 1.000 & \\
\hline 3 & 67.500 & 32.500 & 0.000 & 5752 & 1.000 & \\
\hline 4 & 66.188 & 29.375 & 4.437 & 5818.52 & 1.000 & \\
\hline 5 & 64.239 & 17.386 & 18.375 & 5913.83 & 1.000 & \\
\hline 6 & 64.798 & 35.202 & 0.000 & 5864.42 & 1.000 & \\
\hline 7 & 65.633 & 22.491 & 11.877 & 5874.96 & 1.000 & \\
\hline 8 & 64.281 & 25.048 & 10.671 & 5840.73 & 1.000 & \\
\hline 9 & 66.534 & 26.462 & 7.004 & 5824.38 & 1.000 & \\
\hline 10 & 73.306 & 0.000 & 26.694 & 6296.31 & 1.000 & \\
\hline 11 & 63.763 & 26.115 & 10.121 & 5824.41 & 1.000 & \\
\hline 12 & 63.943 & 36.057 & 0.000 & 5878.37 & 1.000 & \\
\hline 13 & 70.412 & 8.294 & 21.294 & 6105.48 & 1.000 & \\
\hline 14 & 68.427 & 5.111 & 26.462 & 6319.38 & 1.000 & \\
\hline 15 & 67.365 & 28.137 & 4.499 & 5779.45 & 1.000 & \\
\hline 16 & 67.856 & 14.162 & 17.982 & 6011.06 & 1.000 & \\
\hline 17 & 69.770 & 14.614 & 15.616 & 5910 & 1.000 & \\
\hline 18 & 67.194 & 25.451 & 7.355 & 5811.58 & 1.000 & \\
\hline 19 & 71.075 & 11.336 & 17.589 & 5930.51 & 1.000 & \\
\hline 20 & 60.234 & 39.675 & 0.091 & 5816.27 & 1.000 & \\
\hline 21 & 69.511 & 3.526 & 26.963 & 6363.85 & 1.000 & \\
\hline 22 & 62.726 & 23.015 & 14.259 & 5787.06 & 1.000 & \\
\hline 23 & 65.128 & 28.157 & 6.715 & 5838.27 & 1.000 & \\
\hline 24 & 62.317 & 23.736 & 13.947 & 5760.23 & 1.000 & \\
\hline 25 & 63.451 & 8.817 & 27.732 & 6039.81 & 1.000 & \\
\hline 26 & 62.899 & 16.302 & 20.799 & 5854.67 & 1.000 & \\
\hline 27 & 62.362 & 3.194 & 34.444 & 6092.7 & 1.000 & \\
\hline 28 & 69.100 & 0.574 & 30.326 & 6518.68 & 1.000 & Selected \\
\hline 29 & 69.717 & 1.962 & 28.322 & 6432.89 & 1.000 & \\
\hline 30 & 66.294 & 30.784 & 2.922 & 5812.38 & 1.000 & \\
\hline 31 & 67.625 & 19.073 & 13.301 & 5897.07 & 1.000 & \\
\hline 32 & 70.944 & 8.583 & 20.473 & 6056.12 & 1.000 & \\
\hline
\end{tabular}


process, the design-expert software examined the conditions for increasing the passivation time by changing the furnace load in the melting plant. Based on the proposed model, the software has proposed different optimal combinations for the furnace load to increase the passivation time, assuming that the chemical composition of the furnace load components (concentrate, refinery scrap, and non-refinery scrap) is constant. As shown, all compounds have similar passivation time close to each other. According to the results provided in Table 6 , combination of 28 of this table has the longest passive time, which is equal to 6518 s. Also, the proposed composition of this sample is equal to $69.1 \mathrm{wt}$. \% of concentrate, $0.574 \mathrm{wt} . \%$ of refinery scrap, and $30.326 \mathrm{wt} . \%$ of non-refinery scrap.

Figure 5 shows the chronopotentiometry diagrams of the proposed anode composition. It can be concluded that this sample has high passivation time in contrast with the other samples. The passivation time of this sample is $6520 \mathrm{~s}$, which is close to the software estimated passivation time of $6518 \mathrm{~s}$.

The chemical composition of the optimum anode is shown in Table 7. It seems that the higher As dopant in the melting unit proportion to the amount of NRS can effectively suppress the higher potential of passivation in the electrorefining cell.

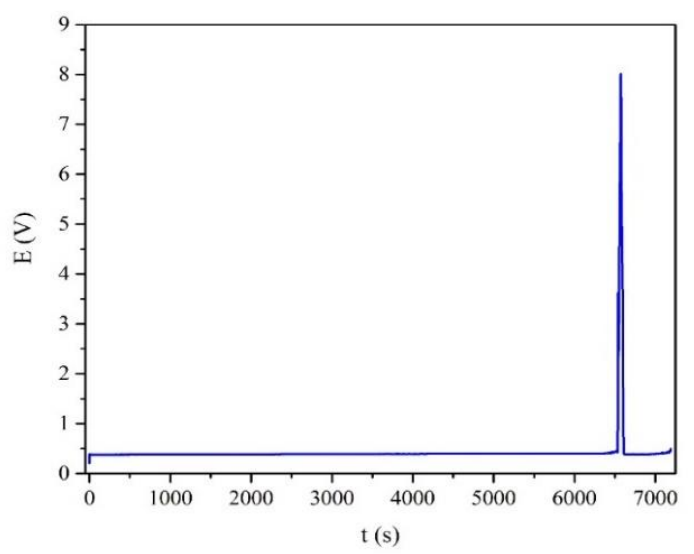

Figure 5. Chronopotentiometry diagrams of the proposed anode at the optimal composition

TABLE 7. The chemical composition of the optimum anode

\begin{tabular}{|c|c|c|c|c|c|c|c|c|c|c|c|c|c|c|c|c|c|c|c|c|c|}
\hline & $\% \mathrm{Cu}$ & $\mathbf{P}$ & $\mathbf{S}$ & $\mathbf{T e}$ & As & Se & $\mathbf{S b}$ & Cd & $\mathrm{Cr}$ & $\mathbf{P b}$ & $\mathbf{S i}$ & $\mathbf{B i}$ & $\mathbf{A g}$ & $\mathbf{Z n}$ & $\mathbf{N i}$ & Co & $\mathbf{F e}$ & $\% \mathrm{O}_{2}$ & $\mathbf{A u}$ & Sn & Mn \\
\hline $\begin{array}{l}\text { Optimal } \\
\text { condition }\end{array}$ & 99.66 & $<0.5$ & 2.76 & 24 & 515 & 70.1 & 342 & $<0.5$ & $0.5>$ & 310 & $<0.5$ & 113 & 220 & 21.36 & 501 & $<0.5$ & 30.2 & 0.14 & 7.20 & 44.17 & $<0.5$ \\
\hline
\end{tabular}

\section{CONCLUSION}

The present study shows that the chemical composition of the anode has a significant effect on the process of anode passivation. The chemical composition of the anode is determined in the casting stage, i.e., a function of the charging of the melting furnace. Accordingly, if the chemical composition of the furnace load components is constant, which includes concentrate, refinery scrap, and non-refinery scrap, the optimal fraction of the furnace load components can be obtained by the design of experiment to achieve the maximum time of anode passivation. According to the operational scope of the study, the optimal combined charge composition is $69.1 \%$ concentrate, $0.574 \%$ refinery scrap, and $30.326 \%$ non-refinery scrap to achieve of 6520 seconds passivation time by $220 \mathrm{~mA} / \mathrm{cm}^{2}$ current density. The results of this study also showed that the $\mathrm{As} /(\mathrm{Bi}+$ $\mathrm{Sb})$ ratio is a good criterion for comparing the passivity of the samples, and higher values of this ratio of 4 mean an increase in the start time of the passivation. Also, the higher value of this ratio can effectively compensate the deteriorating effect of non-refinery scrap impurities in the charge of the melting furnace.

\section{REFERENCES}

1. Schlesinger, M.E., King, M.J. and Davenport, W.G., "Extractive metallurgy of copper, Elsevier, (2011), doi: 10.1016/C2010-064841-3.

2. Jackson, E., "Hydrometallurgical extraction and reclamation, Ellis Horwood Chichester, Vol. 204, (1986), doi: 10.1002/aic.690330923.

3. Li, L., Li, H.-j., Qiu, S.-w. and Wang, H., "Effect of additives on anode passivation in direct electrolysis process of copper-nickel based alloy scraps", Journal of Central South University, Vol. 25, No. 4, (2018), 754-763, doi: 10.1007/s11771-018-3780-1.

4. Jarjoura, G. and Kipouros, G.J., "Electrochemical studies on the effect of nickel on copper anode passivation in a copper sulphate solution", Canadian Metallurgical Quarterly, Vol. 45, No. 3, (2006), 283-294, doi: 10.1179/cmq.2006.45.3.283.

5. Safizadeh, F. and Ghali, E., "Monitoring passivation of $\mathrm{cu}-\mathrm{sb}$ and $\mathrm{cu}-\mathrm{pb}$ anodes during electrorefining employing electrochemical noise analyses", Electrochimica Acta, Vol. 56, No. 1, (2010), 93 101, doi: 10.1016/j.electacta.2010.09.046.

6. Safizadeh, F. and Ghali, E., "Electrochemical noise of copper anode behaviour in industrial electrolyte using wavelet analysis", Transactions of Nonferrous Metals Society of China, Vol. 23, No. 6, (2013), 1854-1862, doi: 10.1016/S1003-6326(13)62670-9.

7. Moats, M.S. and Hiskey, J.B., "The role of electrolyte additives on passivation behaviour during copper electrorefining", Canadian Metallurgical Quarterly, Vol. 39, No. 3, (2000), $297-$ 306, doi: 10.1179/cmq.2000.39.3.297. 
8. Moats, M.S., Hiskey, J.B. and Collins, D.W., "The effect of copper, acid, and temperature on the diffusion coefficient of cupric ions in simulated electrorefining electrolytes", Hydrometallurgy, Vol. 56, No. 3, (2000), 255-268, doi: 10.1016/S0304-386X(00)00070-0.

9. Minotas, J.C., Djellab, H. and Ghali, E., "Anodic behaviour of copper electrodes containing arsenic or antimony as impurities", Journal of Applied Electrochemistry, Vol. 19, No. 5, (1989), 777-783, doi: 10.1007/BF01320654

10. Bounoughaz, M., Manzini, M. and Ghali, E., "Behaviour of copper anodes containing oxygen, silver and selenium impurities during electro-refining", Canadian Metallurgical Quarterly, Vol. 34, No. 1, (1995), 21-26, doi: 10.1179/cmq.1995.34.1.21.

11. Abe, S., Burrows, B. and Ettel, V., "Anode passivation in copper refining", Canadian Metallurgical Quarterly, Vol. 19, No. 3 , (1980), 289-296, doi: 10.1179/cmq.1980.19.3.289.

12. Chen, T.T. and Dutrizac, J.E., "A mineralogical study of the deportment and reaction of silver during copper electrorefining", Metallurgical and Materials Transactions B, Vol. 20, No. 3 , (1989), 345-361, doi: 10.1007/BF02696987.

13. Sẹdzimir, J. and Gumowska, W., "Influence of electrolysis variables on the passivation time of copper anodes in copper electrorefining", Hydrometallurgy, Vol. 24, No. 2, (1990), 203 217, doi: 10.1016/0304-386X(90)90087-I.

14. Cheng, X. and Hiskey, J.B., "Fundamental studies of copper anode passivation during electrorefining: Part i. Development of techniques", Metallurgical and Materials Transactions B, Vol. 27, No. 3, (1996), 393-398, doi: 10.1007/BF02914903.

15. Box, G.E.P. and Wilson, K.B., "On the experimental attainment of optimum conditions", Journal of the Royal Statistical Society: Series B (Methodological), Vol. 13, No. 1, (1951), 1-38, doi: 10.1111/j.2517-6161.1951.tb00067.x.

16. Khaskhoussi, A., Calabrese, L., Bouhamed, H., Kamoun, A. Proverbio, E. and Bouaziz, J., "Mixture design approach to optimize the performance of tio2 modified zirconia/alumina sintered ceramics", Materials \& Design, Vol. 137, (2018), 1-8, doi: 10.1016/j.matdes.2017.10.010.

17. Khazaei Feizabad, M.H., Sarvestani, E. and Khayati, G.R., "Modeling and optimization of chemical composition of nano/amorphous fea.Nib.Nbc.Zrd alloy prepared via high-energy ball milling with enhanced soft magnetic properties; a mixture design approach", Journal of Alloys and Compounds, Vol. 841, No., (2020), 155646, doi: 10.1016/j.jallcom.2020.155646.

18. Zhang, D., Zhang, Z., Cheng, T. and Zhao, X., "Multi-factorial analysis on vault stability of an unsymmetrically loaded tunnel using response surface method", International Journal of Engineering, Transactions B: Applications, Vol. 32, No. 11, (2019), 1570-1576, doi: 10.5829/IJE.2019.32.11B.08.

19. Mahmood Ali, S., "Optimization of centrifugal casting parameters of alsi alloy by using the response surface methodology", International Journal of Engineering, Transactions B: Applications, Vol. 32, No. 11, (2019), 15161526, doi: 10.5829/IJE.2019.32.11B.02.

20. Yousefi, M., Safikhani, H., Jabbari, E., Yousefi, M. and Tahmsbi, $\mathrm{V}$., "Numerical modeling and optimization of respirational emergency drug delivery device using computational fluid dynamics and response surface method", International Journal of Engineering, Transactions B: Applications, Vol. 34, No. 2 , (2021), 547-555, doi: 10.5829/IJE.2021.34.02B.28.

21. Eriksson, L., Johansson, E. and Wikström, C., "Mixture designdesign generation, pls analysis, and model usage", Chemometrics and Intelligent Laboratory Systems, Vol. 43, No. 1-2, (1998), 1 24, doi: 10.1016/S0169-7439(98)00126-9.

22. Muteki, K., MacGregor, J.F. and Ueda, T., "Mixture designs and models for the simultaneous selection of ingredients and their ratios", Chemometrics and Intelligent Laboratory Systems, Vol 86, No. 1, (2007), 17-25, doi: 10.1016/j.chemolab.2006.08.003.

23. Petkova, E.N., "Mechanisms of floating slime formation and its removal with the help of sulphur dioxide during the electrorefining of anode copper", Hydrometallurgy, Vol. 46, No. 3, (1997), 277-286, doi: 10.1016/S0304-386X(97)00024-8.

\begin{tabular}{|c|}
\hline Persian Abstract \\
\hline 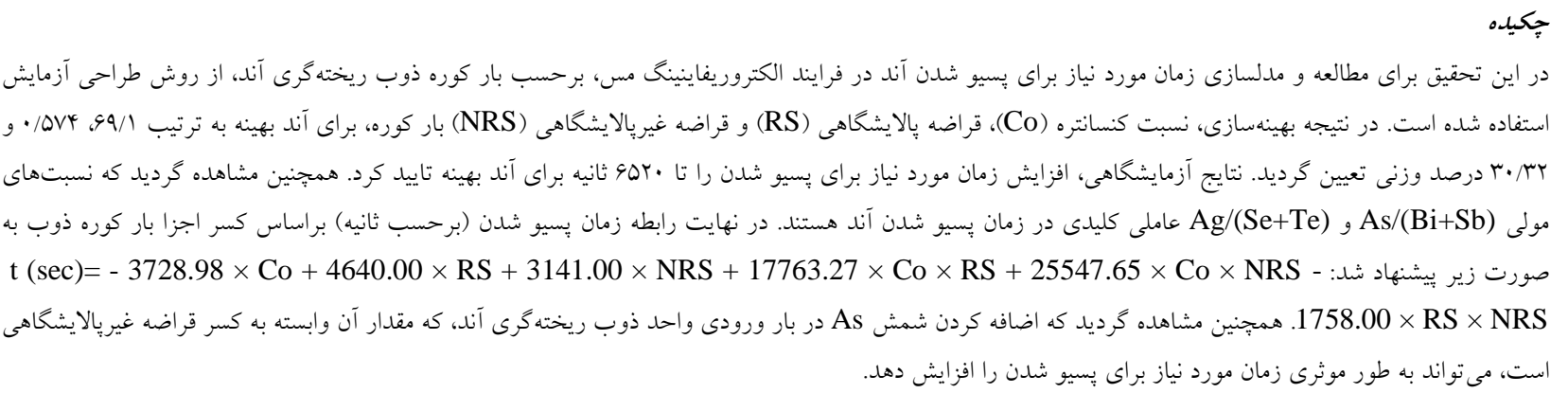 \\
\hline
\end{tabular}

